УДК $811.511 .132 ’ 282 ’ 367.634$

\title{
Э.H. Попова
}

\section{СОЮЗЫ ВРЕМЕННОГО ЗНАЧЕНИЯ В ДИАЛЕКТАХ КОМИ ЯЗЫКА}

Актуальность настоящей работы связана с малоизученностью союзов в диалектах коми языка. Исследование союза актуально не только в связи с решением вопросов формирования союза как части речи, но и с решением вопросов, связанных с осложнением предложения, а вместе с тем синтаксического строя языка.

Ввиду отсутствия описаний союзов в диалектах коми языка мы продолжаем вести исследования по проблеме «Союзы в коми-зырянских диалектах» с тем, чтобы в дальнейшем на основе таких описаний создать работы обобщающего характера.

Объектом исследования являются союзы временного значения, функционирующие в диалектах коми языка. Научная новизна исследования состоит в том, что впервые рассмотрению подвергнуты ранее не описанные в диалектах коми языка союзы временного значения. Выявлен их состав в диалектах; установлены происхождение, способы и пути их образования, генетическая связь с другими частями речи; определены структурные особенности, специфика их употребления в предложении.

В ходе исследования использованы описательно-аналитический, сравнительно-сопоставительный, этимологический методы, метод лексикографического поиска.

Ключевые слова: коми-зырянские диалекты, коми литературный язык, союзы, диалектный синтаксис.

DOI: $10.35634 / 2412-9534-2021-31-6-1170-1177$

На сегодняшний день в коми языке имеется специальное исследование, посвященное союзам, «Союзы и союзные средства в коми языке» [18], в котором дифференцируются наиболее важные этапы в развитии союзов как части речи; выявлены пути и способы их образования, происхождение, значение, структура, анализируется грамматическая семантика, выявляются функциональные особенности. Определены взаимоотношения союзов с другими частями речи, роль влияния контактирующего русского языка на развитие и пополнение корпуса союзных средств. Выявлено общее специфическое в функционировании союзов в коми языке и севернорусских говорах. Освещены вопросы о некоторых типах показателей связи в коми языке, функционально сближающихся с союзами; разграничения союзов от несоюзов, союзных соединений от составных союзов. Между тем, служебные слова, в том числе и союзы, в диалектах коми языка до сих пор не привлекли к себе должного внимания исследователей.

Союзы как часть речи выделены во всех монографиях о коми-зырянских диалектах, авторы ограничиваются разграничением их синтаксических особенностей на сочинительные и подчинительные. Более глубоких специальных исследований не имеется; не разработаны вопросы о происхождении, формировании, развитии союзов в диалектах коми языка. В этой связи стоит отметить лишь статью Э.Н. Поповой «Роль севернорусских говоров в формировании союзов условного значения в коми-зырянских диалектах», в которой рассмотрены ранее не описанные заимствованные из севернорусских говоров союзы ежели, коли, союз-частица так (дак) и укрепившиеся в коми-зырянских диалектах [17, с. 739-744].

Подчинительные союзы, как и в литературном коми языке, подразделяются на следующие семантические группы: временные, причинные, условные, уступительные, сравнительные, целевые, изъяснительные .

Объектом исследования настоящей работы является одна из микросистем подчинительных союзов в диалектах коми языка - союзы временного значения. Выбор названной семантической группы союзов в качестве объекта исследования определяется их неразработанностью в диалектах и говорах коми языка.

Целью работы является выявление состава союзов временного значения, функционирующих в диалектах коми языка; установление происхождения, способов и путей их образования, генетической связи с другими частями речи; определение функционально-семантических, структурных особенностей.

В работе используются описательно-аналитический, сравнительно-сопоставительный, этимологический методы, метод лексикографического поиска. 
Материал собран из словарей коми-зырянского языка, опубликованных образцов комизырянской речи, диалектных источников, фольклорных текстов.

Основными союзами с временным значением в диалектах коми языка являются: муртса (муртсук, муртсить) 'только что; едва; лишь только', мыйӧн (мыйэн, мӧйӧн) 'как только; лишь только; едва', пӧка 'пока', чэм 'как только', кор 'когда если ', да 'когда'.

Союз муртса сформировался на базе наречия муртса 'едва, еле', не связанного с материальным признаком, в силу утраты категориального значения [18, с. 66]. Наречие муртса может примыкать к прилагательному и глаголу. Примыкая к прилагательному, обозначает степень проявления признака, качества, состояния: муртса ловъя 'еле живой', муртса югыд 'чуть светло' и т. д. В предложении, примыкая к глаголу-предикату, наречие муртса может выражать: 1. Степень проявления действия: Бать мудзӧмысла муртса воис гортӧдзыс 'Отец от усталости еле дошел до дому'; Тӧлыс муртса лӧнис 'Ветер чуть утих'. 2. Количественную сторону действия: Муртса пыралі орччӧн олысьясас 'Чуть (совсем ненадолго) заходил(а) к соседям' - указывает на маленький отрезок времени; Вотӧссӧ вайис муртса 'ягоды принес(ла) чуть (совсем мало)' - указывает на малое количество. Его происхождение наложило отпечаток на выражение значения количественности. Наречие муртса является производной и структурно состоит из 2-х частей: корневого мурт- и архаического суффикса -ca. В современном коми языке встречается ряд слов такого же корня: муртавны 'мерить, смерить; вымерить; промерить; обмеривать; диал. снять мерку'; муртавтӧм 'неизмеримый'; мурталысь 'меряльщик'; муртӧс 1) 'мера; критерий’; 2) 'мерка'; 3) диал. 'выкройка'; муртӧса 'учитываемый мерой, мерный’ [8, с. 408]. Во всех этих словах общим семантическим компонентом является «мера». 3. Временной признак со значениями 'едва, только что': Муртса помасисны урокъяс 'Только что закончились уроки', Артистъяс муртса воисны 'Артисты только что приехали'. Предпосылкой для превращения наречия муртса в союз было его закрепление строго фиксированного места в порядке слов - непосредственное примыкание к глаголу-предикату. Возможно, переход наречия муртса в союз произошел следующим образом: были глагольные конструкции, где наречие муртса могло стоять перед глаголом, даже в начале предложения. Употребление наречия муртса со следующим за ним глаголом-предикатом в абсолютном начале бессоюзных конструкций типа Муртса петім туйо̆, заводитіс зэрныл 'Едва только отправились в дорогу, начался дождь', между частями которых существовала синтаксически не выраженная временная зависимость, явилось предпосылкой для превращения его в союз. Наречие муртса, начинавшее сложное бессоюзное предложение, приобретало синтаксическую функцию подчинительного союза с временным значением.

Происхождение союза муртса наложило отпечаток на его значение. В значении наречия мур$m c a$ и союза муртса имеется общий семантический компонент - указание на малое количество. Союз муртса 'едва, едва только, лишь только' используется для выражения разновременности событий, указывает на маленький промежуток времени между действиями предикативных частей.

Союз муртса 'едва, едва только, лишь только', фиксируется в монографиях по верхневычегодскому, печорскому и присыктывкарскому диалектам [2, с. $125 ; 16$, с. $47 ; 19$, с. 187], однако без соответствующих примеров. В письменной речи коми языка употребляется не так часто.

Конструкции с союзом муртса можно встретить в поэтических произведениях коми поэта и драматурга В.А. Савина, творчество которого относится к первой половине ХХ в. Употребление В.А. Савиным данного союза, по нашим соображениям, не случайно. Он является носителем верхневычегодского диалекта, использует в своих поэтических произведениях конструкции с союзом муртса не только с целью ритмической организации стихов, но и показывая стилистическую ценность этого союза. Союз муртса обладает определенной стилистической окраской, которая наслаивается на его основное, грамматическое значение. Происхождение союза муртса наложило отпечаток не только на его грамматическое значение, но и на стилистическую окраску. Само слово-источник - наречие муртса 'едва, еле' - квалифицирующееся как определительное наречие, обозначающее степень проявления качества или действия [15, с. 429-430], имеющее семантический компонент «малое количество», является стилистически маркированным словом. Примеры:

1. Муртса сувті ас кок йылӧ, Удж пыр меным вичмис

$[23$, c. 30$]$.
'Только на ноги поднялся -

Мне по горло дела'

[22, c. 14]. 
2. Ставным на ми тӧдам

Ичӧтдырся олӧм.

Муртса сувтны мӧдам

Кьлӧ миян тольгӧм:

«Сёньдибанӧй, ольӧмӧй...»

(Дзӧбыльтӧмӧн.)

$[23$, c.31]

3. Муртса пӧрччис паськыд раса,

Тур-тармуні ӧшинь тасӧ, -

Якӧ бовгис!..

$[23$, c. 120$]$.
'Часто детство вспоминаем:

Чуть мы на ноги встаем,

Лепетать уж начинаем,

Вслед за взрослыми поем:

«Сёнселикая ты, зизнь...»'

(Шепеляво, сюсюкая.)

$[22$, c. 14].

'Только снял небрежно рясу -

Суматоха началася -

Зазвонили!..'

$[22$, c. 55].

В верхневычегодском диалекте союз муртса имеет вариативную форму муртсук (Ан. Вочь. Крч. Руч) 'только что': Муртсук йугидис кутис тӧтчини, ми мӧдэтчим туйэ 'Едва стало светать, мы отправились в путь' [2, с. 125]. В данном диалекте в форме муртсук может употребляться наречие муртса 'еле'[2, с. 118].

Наречие муртса 'еле' может присоединять к себе суффикс -yк, употребляющийся в коми языке только в определенной группе существительных (пи-ук 'сынок', ныл-ук 'доченька', йо̆й-ук 'дурашка' и т.д.), квалифицирующийся как суффикс субъективной оценки с ласкательным значением [24, I, с. 151]. Суффикс -ук в наречие муртсук вносит уменьшительное значение. При этом наречие муртсук реализует значение 'чуть-чуть, чуточку'.

На базе наречия муртсук формируется союз. Если союз муртса указывает на маленький промежуток времени между действиями предикативных частей в сложноподчиненных предложениях, союз муртсук 'чуть' указывает на минимальный промежуток времени между действиями предикативных частей.

По происхождению союз мыйӧн является застывшей формой местоимения мый- творительного падежа (инструменталя) (-ӧн). Основой формирования временного союза мыійӧн 'как только' могло послужить временное значение инструменталя: первоначально на основе местоимения мый 'что' и временного значения инструменталя - ӧн образуется обстоятельственное слово мыйӧн, имеющее временной признак со значением 'как только'. Позже это обстоятельственное слово переходит в союз $[18$, c. 65-66].

Союз мыйӧн 'как только', характерный для литературного коми языка, бытует также в присыктывкарском, вымском, верхневычегодском, удорском диалектах. Примеры: скр. Мыйӧн ыджыд пач ваймас, ичӧтсӧ лонта 'Как только истопится большая печка, затоплю маленькую' [19, с. 187]; вым. Мыйӧн водис, сидзи и унмоос'ис К. 'Как только лег, так и заснул', Мыйӧн вис'тали, пыр и дзӧӧйооны куччис с'инваыс В. 'Как только я сказала, у нее сразу навернулись слезы' [3, с. 164]; вв. Мыйӧн ная усинь, Педот стрелеч бӧр бергӧдчис и вовис ас пристаньё [4, с. 191] 'Как только они [опяневшие люди] упали, Федот стрелеи обратно повернул и вернулся в свою пристань'; уд. Мыйӧн шуйис сійӧ [Митрей] кывсӧ, ош вомлала кӧттшиоб вартіс 'Только он [Дмитрий] вымолвил это слово, медведь перебежал дорогу' [14, с. 258], Мыйӧн сюмӧдыс чаркнитіс, бурас ӧзйис, оикыл и повзис, вӧлись тӧлькӧ гатимоз лэбӧтьчис бӧрӧ, виркнитіс да иг и адьдзылӧ, сідз и вартіс, саялі 'Как только береста вспыхнула, медведь испугался, запрокидываясь назад, вскинулся, и мы не успели глазом мигнуть, как убежал и скрылся' [14, с. 258, 259]. В верхнесысольском диалекте представлен фонетическим вариантом мӧйӧн 'как только' [5, с. 150]: Мӧйӧн воан, сразу пач лонт Кг. 'Как только придешь, сразу затопи печку', Мӧйӧн води, стразу онмэс'с'и Кб. 'Как только лег, сразу заснул' [5, с. 151]. В ижемском диалекте фиксируется фонетический вариант мыйэн 'как только, лишь только, едва' (7, с. 112): Мыйэн ме кыли, мимэ локти 'Как только я услышал, сразу пришел', Мыйэн пэта ыллла вылэ, кынтэ 'Как только выйду на улицу, знобит' (7, с. 113). Вариант мыйэн фиксируется также в верхневычегодском диалекте [2, с. 231]: Мыйэн муналасни, сийа Пипириски-Сӧкэл динэ пэтоллас (найа вӧли тӧдсас'), шӧк тыв плат'т'эсэ пас'талас и вичко мунас 'Как только все ушли, она зашла к Пипириски-Соколу (они были знакомы), надела платье из шелковой кисеи и пошла в церковь' [2, с. 231, 232].

Союз мыйӧн и его фонетические варианты мӧйӧн, мыйэн в диалектной речи коми языка какихлибо отличий в семантическом и структурном отношениях не проявляют. В построениях с союзом 
мыйӧн и его фонетических вариантов, как и в литературном языке, в сложноподчиненных предложениях между главной и придаточной частями передается значение разновременности действия.

В литературном коми языке союз мыйӧн в придаточном предложении занимает позицию перед придаточной частью. В диалектной речи может располагаться не только в начале придаточной части, но и в середине, что можно объяснить особенностью диалектного синтаксиса. Напр.: Пыblcян мыйӧн вӧдитсис, вовисны вокъяс, зэв гырысь богатыръяс [4, с. 192] 'Баня как только растопилась, пришли братья, очень большие богатыри'. Приведенная конструкция представляет собой структуру, сложившуюся в разговорной речи. Перед нами структура, в которой подчиненность одного предложения другому не выражена с достаточной отчетливостью. При этом мыйӧн, как нам кажется, тяготеет к сказуемому вӧдитсис 'растопилась'. Такая структура сложного предложения отражает, по-видимому, тот период развития сложноподчиненного предложения, когда на базе бессоюзия, как более раннего типа сочетания простых предложений, стало формироваться подчинение. Это предположение подкрепляется тем, что, согласно Э.Н. Поповой, первоначально на основе местоимения мый 'что' и временного значения инструменталя на -ӧн образуется обстоятельственное слово мыйӧн, имеющее временной признак со значением 'как только’. Позже это обстоятельственное слово переходит в союз [18, с. 65-66].

В монографии по печорскому диалекту фиксируется союз сӧмын со значением 'только' [16, c. 47], однако обнаружить пример с союзом сӧмылн нам не удалось.

Локально ограниченным в зырянских диалектах является заимствованный из русского языка союз пока (пӧка) 'пока'. Он представлен в лузско-летском диалекте [10, с. 110; 9, II, с. 180].

Союз пока (пӧка) 'пока' употребляется также в литературном коми языке. Каких-либо отличий в семантическом и структурном отношениях в диалекте не проявляет. Как и в литературном коми языке, он выражает отношение ограничительной одновременности двух действий. лл. Пӧка c’uнмbld вос 'са, вэк колӧ Лет. 'Пока глаза открыты (пока жив) все что-то надо' [10, с. 112; 9, II, с. 180$].$

Надо полагать, что союз пока (пӧка) представляет собой позднее заимствование. Он неизвестен в памятниках древнепермского языка, в грамматиках коми-зырянского языка ХІХ в. [29; 21; 11.].

В лузско-летском, удорском диалектах бытует союз чем (чэм) со значениями 'как только, лишь только, едва' [10, с. 110; 9, II, с. 694]: Чем вои, пьр и сеті Удор 'Как только я пришел, сразу отдал' [9, II, с. 694]; лл. Чем уличӧ пета, кынтӧ Зан. 'Как только выйду на улицу, меня знобит' [9, II, с. 694], Чэм лактис, друг кориснь уджалны Пр. 'Как только приехал, сразу пригласили на работу’ [10, с. 112]. Союз чэм (как это наблюдалось и по отношению союза мыйӧн ) может стоять в начале придаточного предложения и внутри его, напр.: лл. Лымйыд чэм сылӧ, мырпоныл чвэт'итӧ н'ин Пор. 'Как только снег растает, морошка уже цветет' [10., с. 112].

Союз чем (чэм) имеет русское происхождение. В языке-источнике употребляется в литературном языке и русских народных говорах. Словари и грамматики русского языка выделяют сравнительное значение союза чем как основное; он употребляется при оформлении компаративных конструкций и вводит как сравнительные обороты, так и предикативные единицы $[27, \mathrm{IV}, \mathrm{c.} 661 ; 1$, с.1471; 26, III, с. 218]. В грамматике «Современный русский язык» отмечается, что союз чем может очень тесно сливаться с наречиями раньще, прежде (особенно с последним), образуя с ними сочетания, близкие к сложным союзам. В этом случае сложноподчиненные предложения приближаются по значению к временным: Нужно успеть вернуться, прежде чем нас заметят. Ср. Нужно успеть вернуться, пока нас не заметили [26, III, с. 218].

Союз чем с фонетической адаптацией (чим, чэм) имеет соответствие в кондопожских говорах Карелии со значениями 'прежде чем, до того как’ [25, с. 769; 6.]: Чим начать ткать, концьь пропускают [25, с. 769].

Однако союз чем (чэм, чим) в диалектах коми языка и кондопожских говорах Карелии, реализующий между предикативными частями в сложноподчиненных конструкциях временные отношения, имеет разную семантику и происхождение.

В кондопожских говорах Карелии союз чем (чим) утвердился, полагаем, как способ к упрощению сочетания прежде чем при воспроизведении просторечия, в целях экономии речевых средств.

В коми-зырянских диалектах в качестве источника для выражения временной зависимости между предикативными частями сложноподчиненных предложений послужил союз чем (чэм) со значением ‘как только, лишь только, едва только', синонимичный коми союзу мыйӧн 'как только'. Отрываясь от языка- источника и укореняясь в лексической системе диалектов коми языка слово чем (чэм) стало использоваться в синтаксической сфере, и в соответствии с этим происходило изменение в ее 
семантической структуре. В воспринимающем языке слово чем (чэм) закрепилось в значении, которое оно не имело в языке-источнике. Наблюдения показывают: чаще слово заимствуется с прямым значением. Здесь, по-видимому, диалектная речь коми языка усваивает то значение, в котором испытывает определенную потребность в данный момент.

Союз кор 'когда' сформировался на основе местоименного наречия кор 'когда', образовавшегося путем сложения прауральского местоимения *ко и существительного дыр 'время’, восходящего к общепермскому периоду. В результате этого процесса образовалось сложное наречие коддыр $>$ кодыр, впоследствии кодыр > кор. Союз кор является стяженной формой от слова кодыр [13, с. 50; 20, с. 30].

В современном коми литературном языке сложноподчиненные предложения с союзом кор распространены во всех стилях речи. Согласно Н.Д. Мановой, употребление кодыр характерно для художественного стиля, особенно для поэтической речи [13, с. 53].

Исследование фольклорного и диалектного материала, отражающего народную речь, показывает, что союз кор малоупотребителен в народной речи; его вариант кодыр крайне неупотребителен.

Союз кор 'когда' недифференцированного временного значения, функционирующий в литературном коми языке, в сложноподчиненных предложениях передающий помимо значения одновременности значение непосредственного следования (предшествующим является действие, выраженное в придаточной части) [18 с. 68], фиксируется в лузско-летском, удорском, ижемском диалектах. Примеры: лл. Бӧртінас, кор челядь онмысисны, ме гӧтырлӧ висьталі, итӧ ме вайи лӧсь 'Позднее, когда дети заснули, я сказал жене, что убил лося' [14, с.169, 170]; уд. Кор идйыл воас да рудзӧгыд, сійӧ вундам 'Когда созреют ячмень и рожь, (мы) это сжинаем' [14, с. 238, 239]; иж. Кор Чупров эштэдіс асьcьыс рӧбетасэ, кӧр чукартэмсэ, пышйим кык отрядэн 'После того, как Чупров закончил свою работу по сбору оленьих стад, мы двумя отрядами бежали’ [14, с. 283, 287].

В приведенных предложениях союз кор передает значение непосредственного следования: предшествующим является действие, выраженное в придаточной части.

Союз кор 'когда', как и в литературном языке, в диалектах чаще занимает позицию перед придаточной частью. В диалектной речи может располагаться и не в начале придаточного предложения (как это наблюдалось и по отношению к союзам мыйӧн, чэм), а в середине, и даже в конце его. При этом кор, по-видимому, тяготеет непосредственно к сказуемому, занимая место либо перед ним, либо после него. Напр.: уд. Гортыл олины кор, сэки вэтлины чумйас Лат. 'Когда жили дома, тогда ходили в чум' [28, с. 101].

В диалектах коми языка широкое распространение имеет семантически не специализированный союз $\partial a$ 'когда, как только; потому что, так как'. Как и в литературном коми языке в сложноподчиненных предложениях между главной и придаточной частями выражает временные и причинные отношения, локализуясь в конце придаточной части, которая обычно располагается после главного предложения. Что касается происхождения: коми союз $\partial a$ восходит к русской частице да выделительного значения. Коми языком из русского была заимствована лишь частица да, переосмысление этой частицы в союз произошло уже в коми языке: [12, с. 90, 100-102]. Союз да 'когда; потому что, так как' < частица да 'да' (< русская частица $\partial a)$. Исследователи затрудняются утверждать что-либо о времени появления предложений такого типа, поскольку нет древних письменных памятников устной спонтанной речи. В настоящее время союз да в подчинительной функции активно употребляется как в книжно-письменном языке, так и в говорах.

Временное значение фиксируется в верхневычегодском, присыктывкарском, ижемском, удорском, печорском диалектах. Каких-либо отличий в семантическом и структурном плане этот союз в диалектах не проявляет. Примеры: скр. Важӧн ми, дас куйим арӧс тыри да, петім нин пӧдельшина удж вылӧ, кирпич вӧчим, медым кыськӧ деньгатор нажӧвитыштны 'Раньше мы, как только исполнится тринадцать лет, уже шли на поденную работу, делали кирпич, чтобы как-нибудь подзаработать денежек' [14, с. 49, 50], Гожӧмыд воас да, туй пасьталаыс толькӧ гудӧкӧн ветлам 'Как настанет лето, ходим с гармошкой во всю ширину улицы' [14. с. 49, 50]; уд. Йонас эд гол'ӧдасны тан, йукӧртчасны да 'Все косточки перемоют, когда соберутся' [28, с. 101], Козйьл йонас кын'н'алас, пачтӧ лонтан да Лат. 'Ель сильно искрит, когда печку ею топишь' [28, с. 101]; печ. Ме вои да, дзоньӧн ставыс гырд, косяллӧма (ош) вӧлсӧ 'Когда я подошел, кругом была кровь, медведь успел задрать лошадь' [14. С. 307, 308].

Изучение диалектных текстов и материала показало: группа союзов временного значения в диалектах коми языка состоит в основном из шести однословных единиц, часто представленных фо- 
нетическими и структурными вариантами: мыйӧн (вс. мӧйӧн, иж. мыйэн) 'как только'; муртса (вв. муртсук, муртсить, муртсись) 'едва, едва только, лишь только'; пӧка (в литературном языке - пока); чем (чэм) 'как только'; кор 'когда'; семантически не специализированного союза да 'когда; как только'. Кроме союза чем (чэм), не получившего широкого распространения в диалектах, остальные функционируют в литературном языке.

В диалектной речи союзы мыйӧн, чем 'как только', кор 'когда' имеют особенность в употреблении: они могут занимать в придаточном предложении нетипичную позицию - располагаться в середине придаточной части, союз кор 'когда' даже в конце её, что объясняется особенностью диалектного синтаксиса.

\section{СОКРАЩЕНИЯ}

Коми-зырянские диалекты и говоры: 1) диалекты: вв. - верхневычегодский диалект, вс. - верхнесысольский диалект, вым. - вымский диалект, иж. - ижемский диалект, лл. - лузско-летский диалект, печ. - печорский диалект, скр. - присыктывкарский диалект, уд. - удорский диалект; 2) говоры: Ан. - говор с. Аныб верхневычегодского диалекта, В. - говор с. Весляна вымского диалекта, Вочь - говор с. Вочь верхневычегодского диалекта, К. - говор дер. Кони вымского диалекта, Кб. - говор с. Кобра верхнесысольского диалектв, Кг. - говор с. Койгородок верхнесысольского диалекта, Крч. - говор с. Керчомья верхневычегодского диалекта, Лат. - говор д. Латьюга удорского диалекта, Зан. - говор с. Занулье лузско-летского диалекта, Лет. - говор с. Летка лузсколетского диалекта, Пр. - говор с. Прокопьевка лузско-летского диалекта.

\section{СПИСОК ЛИТЕРАТУРЫ И ИСТОЧНИКОВ}

1. БТСРЯ - Большой толковый словарь русского языка. СПб.: Норинт, 2001. 1536 с.

2. ВВД - Сорвачева В.А., Сахарова М.А., Гуляев Е.С. Верхнеычегодский диалект коми языка. Сыктывкар, 1966. $256 \mathrm{c}$.

3. ВД - Жилина Т.И. Вымский диалект коми языка. Сыктывкар, 1998. 438 с.

4. ВВСМ - Висер вожса сьыланкывъяс да мойдкывъяс $=$ Песни и сказки Вишеры / сост. И.А. Осипов. Сыктывкар: Коми кн. изд-во, 1986. 256 с.

5. ВСД - Жилина Т.И. Верхнесысольский диалект коми языка. М.: Наука, 1975. 268 с.

6. Гусева Е.Р. Союзы севернорусских говоров: автореф. дис. ... канд. филол. наук. Петрозаводск, 2009.

7. ИД - Сахарова М.А., Сельков Н.Н. Ижемский диалект коми языка. Сыктывкар: Коми кн. изд-во, 1976. 288 с.

8. КРК - Безносикова Л.М., Айбабина Е.А., Коснырева Р.И. Коми - роч кывчукӧр = Коми-русский словарь / Отв ред. Л.М. Безносикова. Сыктывкар: Коми кн. изд-во, 2000. 815 с.

9. КСК ІІ - Безносикова Л.М., Айбабина Е.А., Забоева Н.К., Коснырева Р.И. Коми сёрнисикас кывчукӧр. Словарь диалектов коми языка. Т. 2 / Отв. ред. Л.М. Безносикова. Сыктывкар, 2014. 888 с.

10. ЛЛД - Жилина Т.И. Лузско-летский диалект коми языка. М.: Наука, 1985. 270 с.

11. Лыткин Г.С. Зырянский край при епископах пермских и зырянский язык. СПб., 1889; 2-е изд. М., 1996.

12. Майтинская К.Е. Служебные слова в финно-угорских языках. М.: Наука, 1982. 185 с.

13. Манова Н.Д. Сложноподчиненные предложения с союзами кор, кодыр в коми языке // Коми филология. Сыктывкар, 1975. С. 50-60. (Труды Института языка, литературы и истории. Вып. 18).

14. ОКЗР - Образцы коми-зырянской речи / Под ред. Д.А. Тимушева. Сыктывкар, 1971. 310 с.

15. ӦКК - Ӧнія коми кыв. Морфология = Современный коми язык. Морфология. Сыктывкар: Коми кн. изд-во, 2000. $542 \mathrm{c}$

16. ПД - Сахарова М.А., Сельков Н.Н., Колегова Н.А. Печорский диалект коми языка. Сыктывкар: Коми кн. изд-во, 1976. $151 \mathrm{c}$

17. Попова Э.Н. Роль севернорусских говоров в формировании союзов условного значения в коми-зырянских диалектах // Вестн. Удм. ун-та. Сер. История и филология. 2019. Т. 29, вып. 5. С. 739-744.

18. Попова Э.Н. Союзы и союзные средства в коми языке. Сыктывкар, 2015. $111 \mathrm{c.}$

19. ПСД - Жилина Т.И., Бараксанов Г.Г. Присыктывкарский диалект и коми литературный язык. М.: Наука, $1971.276 \mathrm{c.}$

20. Редеи Карой. Сочинительные и подчинительные союзы коми языка // История, современное состояние и перспективы развития языков и культур финно-угорских народов: Материалы III Всероссийской научной конференции финно-угроведов. Сыктывкар, 2005. С. 228-234.

21. Савваитов П.И. Грамматика зырянского языка. СПб., 1850. 168 с.

22. Савин В.А. Звени, моя парма. Сыктывкар: Коми кн. изд-во, 1983. 255 с.

23. Савин В.А. Майбырӧй, олӧмӧй / Составитель В.В. Тимин. Сыктывкар: Милета, 2008.

24. СКЯ I - Современный коми язык. Ч. І: Фонетика, лексика, морфология / под ред. В.И. Лыткина. Сыктывкар, $1955.312 \mathrm{c}$. 
25. СРГК - Словарь русских говоров Карелии и сопредельных областей. СПб.: Изд-во С.-Петербург. ун-та, 2005. Вып. 6. 992 с.

26. СРЯ 1981 III - Бабайцева В.В., Максимов Л.Ю. Современный русский язык. Учеб. пособ. для студ. в 3-х ч. Ч. III. Синтаксис. Пунктуация. М.: Просвещение, 1981. 271 с.

27. СРЯ 1984 IV - Словарь русского языка. 2-ое изд. М.: Русский язык, 1984. T. IV. 794 с.

28. УД - Сорвачева В.А., Безносикова Л.М. Удорский диалект коми языка. М.: Наука, 1990. 283 с.

29. Флеров А.Ф. Зырянская грамматика, изданная отъ главного правленія училищъ. Санктпетербург, 1813.57 с.

Поступила в редакцию 21.05.2021

Попова Элеонора Николаевна, научный сотрудник

Институт языка, литературы и истории Коми научного центра Уральского отделения РАН

(ИЯЛИ ФИЦ Коми НЦ УрО РАН),

167982, Россия, г. Сыктывкар, ул. Коммунистическая, 26

E-mail: eleonora.20.02@mail.ru

\title{
E.N. Popova \\ CONJUNCTIONS OF TEMPORARY MEANING IN THE DIALECTS OF THE KOMI LANGUAGE
}

\author{
DOI: $10.35634 / 2412-9534-2021-31-6-1170-1177$
}

The relevance of this work is related to the poorly studied conjunctions in the dialects of the Komi language. The study of conjunctions is relevant not only in connection with the solution of the problem of the formation of a conjunction as a part of speech, but also with the solution of problems related to the complication of a sentence, and at the same time, the syntactic structure of the language.

Due to the lack of descriptions of conjunctions in the dialects of the Komi language, we continue to conduct research on the problem of "Conjunctions in the Komi-Zyryan dialects" in order to create generalizing works based on such descriptions in the future.

The object of the study is the conjunctions of temporary meaning that function in the dialects of the Komi language.

The scientific novelty of the study is that, for the first time, the conjunctions of temporary meaning that were not previously described in the dialects of the Komi language, are considered. Their composition in dialects is revealed; the origin, methods and ways of their formation, genetic connection with other parts of speech are established; structural features, peculiarities of their use in a sentence are determined.

In the course of the study, descriptive-analytical, comparative, etymological methods, the method of lexicographic search were used.

Keywords: Komi-Zyryan dialects, Komi literary language, conjunctions, dialect syntax.

\section{REFERENCES}

1. BTSRYA - Bol'shoj tolkovyj slovar' russkogo yazyka [Big explanatory dictionary of the Russian language]. St. Petersburg: "Norint", 2001. 1536 p. (In Russian).

2. VVD - Sorvacheva V.A., Sakharova M.A., Gulyaev E.S. Verhnevychegodskij dialekt komi yazyka [The Upper Vychegda dialect of the Komi language]. Syktyvkar, 1966. 256 p. (In Russian).

3. VD - Zhilina T.I. Vymskij dialekt komi yazyka [The Vym dialect of the Komi language]. Syktyvkar, 1998. 438 p. (In Russian).

4. VVSM - Viser vozhsa s'ylankyv"yas da mojdkyv"yas = Pesni i skazki Vishery / Sostavitel' I.A. Osipov [Songs and fairy tales of Vishera / Compiled by I. A.Osipov]. Syktyvkar: Komi Book Publishing House, 1986. 256 p. (In Komi)

5. VSD - Zhilina T.I. Verhnesysol'skij dialekt komi yazyka [The Upper Sysola dialect of the Komi language]. Moscow: Nauka, 1975. 268 p. (In Russian).

6. Guseva E.R. Soyuzy severnorusskih govorov: avtoref. dis. ... kand. filol. nauk [Conjunctions of the North-Russian dialects: Abstract of diss. ... Cand. Sci. (Philology)]. Petrozavodsk, 2009. (In Russian).

7. ID - Sakharova M.A., Sel'kov N.N. Izhemskij dialekt komi yazyka [The Izhma dialect of the Komi language]. Syktyvkar: Komi Book Publishing House, 1976. 288 p. (In Russian).

8. KRK - Beznosikova L.M., Ajbabina E.A., Kosnyreva R.I. Komi - roch kyvchukör = Komi-russkij slovar' / otv red. L.M. Beznosikova [Komi-Russian dictionary / Ed. L.M. Beznosikova]. Syktyvkar: Komi Book Publishing House, 2000. 815 p. (In Komi). 
9. KSK II - Beznosikova L.M., Ajbabina E.A., Zaboeva N.K., Kosnyreva R.I. Komi syornisikas kyvchukör. Slovar' dialektov komi yazyka. T. 2 / Otv. red. L.M. Beznosikova [Dictionary of dialects of the Komi language. Vol. 2 / Ed. L. M. Beznosikova]. Syktyvkar, 2014. 888 p. (In Komi).

10. LLD - Zhilina T. I. Luzsko-letskij dialekt komi yazyka [The Luza-Letka dialect of the Komi language]. Moscow: Nauka, 1985. 270 p. (In Russian).

11. Lytkin G.S. Zyryanskij kraj pri episkopah permskih i zyryanskij yazyk [Zyryans territory under the bishops of Perm and the Zyryan language]. St. Petersburg, 1889; 2nd ed. Moscow, 1996. (In Russian).

12. Maitinskaya K.E. Sluzhebnye slova v finno-ugorskih yazykah [Official words in the Finno-Ugric languages]. Moscow: Nauka, 1982. 185 p. (In Russian).

13. Manova N.D. Slozhnopodchinennye predlozheniya s soyuzami kor, kodyr v komi yazyke [Complex sentences with conjunctions кор, кодыр in the Komi language] // Komi filologiya [Komi Philology]. Syktyvkar, 1975. P. 50-60. (Trudy Instituta yazyka, literatury i istorii. Vyp. 18 [Proceedings of the Institute of Language, Literature and History. Issue 18]). (In Russian).

14. OKZR - Obrazcy komi-zyryanskoj rechi / Pod red. D.A. Timusheva [Samples of the Komi-Zyryan speech / Ed. D. A. Timushev]. Syktyvkar, 1971. 310 p. (In Russian).

15. OKK - Öniya komi kyv. Morfologiya = Sovremennyj komi yazyk. Morfologiya [Modern Komi language. Morphology]. Syktyvkar: Komi Book Publishing House, 2000, 542 p. (In Komi).

16. PD - Saharova M.A., Sel'kov N.N., Kolegova N.A. Pechorskij dialekt komi yazyka [The Pechora dialect of the Komi language]. Syktyvkar: Komi Book Publishing House, 1976. 151 p. (In Russian).

17. Popova E.N. Rol' severnorusskih govorov v formirovanii soyuzov uslovnogo znacheniya v komi-zyryanskih dialektah [The role of Northern Russian dialects in the formation of conjunctions of conditional meaning in the Komi-Zyryan dialects] // Vestnik Udmurtskogo universiteta. Seriya «Istoriya i filologiya» [Bull. of Udmurt University. Series "History and Philology"]. 2019. Vol. 29. Issue 5. P. 739-744. (In Russian).

18. Popova E.N. Soyuzy i soyuznye sredstva v komi yazyke [Conjunctions and connective means in the Komi language]. Syktyvkar, 2015. 111 p. (In Russian).

19. PSD - Zhilina T.I., Baraksanov G.G. Prisyktyvkarskij dialekt i komi literaturnyj yazyk [Pre-Syktyvkar dialect and Komi literary language]. Moscow: Nauka, 1971. 276 p. (In Russian).

20. Redei Caroi. Redei Karoj. Sochinitel'nye i podchinitel'nye soyuzy komi yazyka [Compositional and subordinate conjunctions of the Komi language] // Istoriya, sovremennoe sostoyanie i perspektivy razvitiya yazykov i kul'tur finno-ugorskih narodov: Materialy III Vserossijskoj nauchnoj konferencii finno-ugrovedov [History, current state and prospects for the development of languages and cultures of the Finno-Ugric peoples: Materials of the III AllRussian Scientific Conference of Finno-Ugrians]. Syktyvkar, 2005. P. 228-234. (In Russian).

21. Savvaitov P.I. Grammatika zyryanskogo yazyka [Grammar of the Zyryan language]. St.Petersburg, 1850.168 p. (In Russian).

22. Savin V.A. Zveni, moya parma [Ring, my parma]. Syktyvkar: Komi Book Publishing House, 1983. 255 p. (In Russian).

23. Savin V.A. Majbyröj, olömöj / Sostavitel' V.V. Timin [Maybyroi, olomoi / Compiled by V.V. Timin]. Syktyvkar: Mileta, 2008. 606 p. (In Komi).

24. SKYA I - Sovremennyj komi yazyk. Ch. I: Fonetika, leksika, morfologiya / Pod red. V.I. Lytkina [Modern Komi language. Part I: Phonetics, vocabulary, morphology / Ed. V.I. Lytkin]. Syktyvkar, 1955. 312 p. (In Russian).

25. SRGK - Slovar' russkih govorov Karelii i sopredel'nyh oblastej [Dictionary of Russian dialects of Karelia and adjacent regions]. St. Petersburg: Publishing house of St. Petersburg . Univ., 2005. Issue 6. 992 p. (In Russian).

26. SRYA 1981 III - Babaytseva V.V., Maksimov L. Sovremennyj russkij yazyk. Ucheb. posob. dlya stud. v 3-h ch. [Modern Russian language. Study guide for students in 3 parts. Part III. Syntax. Punctuation]. Moscow: Prosveshchenie, 1981. 271 p. (In Russian).

27. SRYA 1984 IV - Slovar' russkogo yazyka. 2-oe izd. [Dictionary of the Russian language. 2nd ed.]. Moscow: Russian Language, 1984. Vol. IV. 794 p. (In Russian).

28. UD - Sorvacheva V.A., Beznosikova L.M. Udorskij dialekt komi yazyka [Udora dialect of the Komi language]. Moscow: Nauka, 1990. 283 p. (In Russian).

29. Flerov A.F. Zyryanskaya grammatika, izdannaya ot" glavnogo pravleniya uchilishch" [Zyryan grammar, published by the Department of the Main Board of Schools]. St. Petersburg, 1813. 57 p. (In Russian).

Received 21.05.2021

Popova E.N., Researcher

The Institute of Language, Literature and History of the Komi Research Centre of the Ural Branch

of the Russian Academy of Sciences

Kommunisticheskaya st., 26, Syktyvkar, Russia, 167982

E-mail: eleonora.20.02@mail.ru 